\title{
Histopathological Assessment of the Effect of Pregabalin Toxicity on Cerebrum and Cerebellum of Adult Albino Rats
}

Wael Abdou Hassan ( $\nabla$ w.hassan@sr.edu.sa )

Suliman Al Rajhi University

Shaimaa Shehata

Suez Canal University

Ahmad ElBana

Al Azhar University

\section{Research Article}

Keywords: Pregabalin, cerebral cortex, cerebellum

Posted Date: January 21st, 2021

DOI: https://doi.org/10.21203/rs.3.rs-149289/v1

License: (c) (1) This work is licensed under a Creative Commons Attribution 4.0 International License.

Read Full License 


\section{Abstract}

Background: Pregabalin (PGB) used as analgesic in treatment of neurogenic pains of chronic diseases, is considered as one of the most abused anti-epileptic drugs worldwide and it has been proved that it induces addictive behaviors. The present histopathological study aimed to identify the effect of PGB administration on cerebral cortex and cerebellar cortex, in both acute and chronic toxicity. Seventy-two male and non-pregnant female adult albino rats' 6- to 8-week-old divided into 3 main groups of 24 rats each were studied. Group 1 represented the control group and group 2 represented the acute toxicity group, in which rats were given a single dose of PGB $(5000 \mathrm{mg} / \mathrm{kg})$ orally by gavage and after 24 hours, rats were sacrificed and examined. Group 3 represented the chronic toxicity group; were given PGB 500 $\mathrm{mg} / \mathrm{kg}$ orally by gavage for 12 weeks, after which rats were sacrificed and examined.

Result: Cerebral cortex tissue of acute toxicity group displayed astrocytosis and dystrophic changes, while in chronic group showed degeneration, necrosis and cellular infiltrates. The cerebellum of chronic groups showed degeneration and shrunken of Purkinje cells.

Conclusion: Acute and chronic intoxication with pregabalin adversely altered the structure of cerebral cortex and cerebellum.

\section{Introduction}

Anti-epileptic drugs are one of the most abused drugs worldwide, especially pregabalin (PGB) and gabapentin [1]. PGB is widely used as analgesic in treatment of neurogenic pain in diabetic neuropathy $[2,3]$. It is also approved for the treatment of generalized anxiety disorder, post herpetic neuralgia, posttraumatic stress disorder, seizures, migraine and fibromyalgia [4]. Studies have shown that PGB may also be effective in the treatment of benzodiazepine dependence and alcohol dependence [5].

PGB is considered an "ideal psychotropic drug" to achieve specific effects, including sedation, euphoria, dissociation, and psychoactive effects [6, 7]. The Poison Information Centre in Munich, Germany reported that from 2008 to 2015, 263 patients with PGB abuse history were treated with increase in number of cases per year and PGB was reported to be the $5^{\text {th }}$ most frequently abused substance [8].

Pregabalin is classified as a CNS depressant and its mechanism of toxicity is supposed to be CNS depression with respiratory failure and cardiac complications [9]. Cases with cerebellar dysfunction related to PGB intoxication were reported with high or low dose $[10,11]$. The mechanism for PGB-induced cerebellar dysfunction remains unclear, however some studies stated that PGB could result in functional loss of the cerebellum due to decreased excitatory inputs from the brainstem [12].

This study was conducted to find out the possible histopathological changes of PGB on cerebrum and cerebellum in a rat model experimental study.

\section{Materials And Methods}




\section{Drugs and chemicals:}

All drugs and chemical purchased were listed in supplementary table 1.

\section{Test animals:}

This experimental work was carried out on 72 male and non-pregnant female adult Albino rats 6- to 8week-old weighing 100-150 grams. Rats were housed in plastic cages under standard pathogen free conditions and quite non-stressful special room. Every five rats of same sex were placed in each cage, so that stress of isolation or overcrowding was avoided. The rats are divided into 3 main groups of 24 rats each: Group I (Control group; $n=24$ ): which is further subdivided into subgroup IA (control group for acute toxicity of Pregabalin; $n=12$ ) \& IB (ontrol group for chronic toxicity of Pregabalin; $n=12$ ). Group II (Acute toxicity group; $\mathrm{n}=24)$ were given a single dose of PGB $(5000 \mathrm{mg} / \mathrm{kg}$ body weight) orally by gavage. After 24 hours, rats were sacrificed and subjected to histopathological investigations. Group III (Chronic toxicity group; $\mathrm{n}=24$ ) received chronic doses of PGB as following: $500 \mathrm{mg} / \mathrm{kg}$ orally gavage (equivalent $1 / 10$ LD50) for 12 weeks [13]. The drug solution was given with a volume of 1-2 $\mathrm{ml}$. using a stomach tube gavage.

\section{Histopathological evaluation:}

The organs were isolated and washed with normal saline; small segments of tissues from the normal and experimental rats were preserved in $10 \%$ formalin solution and dehydrated in ascending grades of alcohol. The specimens were then embedded in paraffin blocks, sectioned into 4-5 $\mu \mathrm{m}$ thick and stained with hematoxylin and eosin (H\&E) staining [14].

\section{Results}

Examination of sections of the cerebral cortex (CC) grey and white matter of both control groups showed normal structures of the layers of $\mathrm{CC}$ and its cells. The grey matter was well organized and regularly arranged in six layers from outside inwards: the outer molecular layer was a fibrous layer with few neuroglia and neurons cells, the granular layers consisted of stellate-shaped nerve cells with large round nuclei, the inner and outer pyramidal cell layers were formed of medium and large sized cells, respectively, the innermost layer constitutes the pleomorphic layer and was formed of a variety of nerve cells. Pyramidal cells were seen with large central vesicular nuclei, containing one or more nucleoli and basophilic cytoplasm. Granular cells are seen with large rounded vesicular nuclei while glial cells seen as small dense nuclei. The fibrillary eosinophilic background substance constituted the neuropil, with glial cells and blood vessels within. (Fig. 1A).

Examination of sections of the cerebellum of both control groups showed normal appearance of cerebellar folia: each folium formed of outer gray cortex and inner white matter. The cerebellar cortex 
showed three layers from outside inwards; the molecular layer, the Purkinje cell layer and the granular cell layer. The molecular layer was formed of 2 types of neurons: stellate and basket cells. The Purkinje cells layer arranged in one row between the granular and molecular layers, showed large flask shaped cells with vesicular rounded nuclei with apparent nucleoli and basophilic Nissel's granules in their cytoplasm. The granular layer consisted of closely packed numerous, oval granular cells with deeply stained rounded nuclei (Fig. 2A).

\section{Effect of acute pregabalin toxicity on cerebral cortex (Fig. 1B) and cerebellum (Fig. 2B)}

In acutly intoxicated group II, examination of sections of CC tissue of both male and female groups showed increase in cellularity and irregular distribution of the astrocytes, with hypertrophy and enlarged vesicular nuclei cells. Dystrophic changes in the form of red neurons were seen with shrinkage of the cell body, pyknosis of the nucleus, disappearance of the nucleolus and intense eosinophilia of the cytoplasm. No pathological changes were seen regarding neuropil, blood vessels and layers of CC.

Examination of sections of crebellar tissue of both male and female groups showed preserved architecture of cerebellar cortex layers with few shrunken Purkinje cells. The neuropil had few vacuoles of variable sizes and pericellular haloes. The molecular and granular layers have apparently normal architecture.

\section{Effect of chronic pregabalin toxicity on cerebral cortex (Fig. 1C) and cerebellum (Fig. 2C)}

In chronic intoxicated group, the CC showed multifocal histological changes in all layers of the CC of both male and female groups as compared to the control group. Most of pyramidal cells were shrunken and showed deeply stained nuclei with loss of their processes, and pericellular halos. Many vacuoles of variable sizes were found in neuropil and inside most of cells in all layers. Small focal area of inflammatory infiltrate and necrosis was seen. The CC showed dilated congested blood vessel surrounded by inflammatory infiltrate, area of intracerebral hemorhage and encapsulated necrosis.

Similarly, cerebellar cortex of both male and female groups showed shrinkage of most of Purkinje cells with loss of their processes, and pericellular halos. Many vacuoles of variable sizes were seen in neuropil and inside most of cells in all layers.

\section{Discussion}

Pregabalin toxicity has been related to overdose consumption resulting in suicide, recreation and accidental overdose. Moreover, PGB toxicity may occur after its synergistic depressant effect with other CNS depressant drugs and following accumulation of PGB in the setting of renal impairment [15-17]. 
Accordingly, the present study investigated possible toxic effects of acute and chronic PGB administration on cerebral cortex and cerebellum of adult albino rats.

The brain histopathological changes in the present study showed significant degenerative changes in neurons in both cerebral cortex and cerebellum with hypertrophy and hyperplasia of astrocytes with acute intoxication with PBG. These changes were attributed to the direct effect of PGB on the brain. These results were similar to previous reports of PGB causing encephalopathy and EEG changes [18-20].

In addition, the present study showed degenerative changes in the cerebellar cortex of all chronic PGB intoxicated groups, affecting mainly Purkinje cells, which became shrunken with ill-defined cytoplasmic processes and some of them had vacuolated cytoplasm with absence of Nissel's granules. The molecular and granular layers were also affected, being less in thickness and had multiple vacuolated areas. Such findings agreed with previous reports [21, 22], which reported the chronic effect of administration of $600 \mathrm{mg} / \mathrm{kg}$ PGB to maternal Swiss albino mice and resulted in degenerative effects on developing cerebellum of fetus, in the form of disruption of the architecture of the Purkinje cell layer, mild vacuolization in the granular layer, necrosis and hemorrhage in focal area of white matter.

The cerebellar cortex in chronically treated rats with $500 \mathrm{mg} / \mathrm{kg}$ PGB showed degenerative changes of both Purkinje and granular cells. Purkinje cell became shrunken, disarranged and there was cell loss. Purkinje cells play a crucial role in motor coordination and alteration in structure or functions of these cells may cause changes in motor coordination function [23,24]. There has been some evidence of cerebellar dysfunction in pregabalin intoxication in the form of nystagmus, in-coordination, myoclonus and ataxia [25-28].

The vacuolization appeared in brain tissues of rats in the current study could be attributed to cellular degeneration within the cerebellar and cerebral cortex. In addition, shrunken Purkinje cells were surrounded by large prominent pericellular spaces that could be related to the shrinkage of neurons and disintegration of their cyto-skeletal elements [29]. The dark staining of nuclei of degenerated cells could be due to accumulation of denatured proteins and chromatin condensation in cells undergoing apoptosis [30].

The cerebellar dysfunction in pregabalin intoxication could be attributed to action of PGB on $a 2-\delta$ subunit of VGCC, which are widely distributed throughout the peripheral and central nervous systems. The highest level of expression of these channels has been found in the cerebellum and in the hippocampus, and their dysfunction or decreasedactivity level has been linked to ataxia and cognitive impairment [32].

\section{Declarations}

\section{Ethical approval}

All procedures performed on animals were done in according to the guidelines and approved by committee of ethics in faculty of medicine, Suez Canal university; Egypt (C; No.4521) and in compliance 
with the ARRIVE guidelines. The staff who dealt with the animals were well trained. Animals were fed appropriately and protected from pathogens. Pain, distress, and suffering were kept to a minimum grade. Adequate food and water were introduced to entire animals and they were assessed for general health and body weight. Animals were anesthetized before scarification. Scarification the animals was done in appropriate manner.

\section{Availability of data and material}

All data generated during this study are included in this published article [and its supplementary information files].

\section{Funding}

All studies in this research were funded by the authors.

\section{Competing interests}

No conflict of interest.

\section{Authors' contributions}

All authors made a significant contribution to the work reported, whether that is in the conception, study design, execution, acquisition of data, analysis and interpretation, or in all these areas; took part in drafting, revising or critically reviewing the article; gave final approval of the version to be published; have agreed on the journal to which the article has been submitted; and agree to be accountable for all aspects of the work.

\section{Acknowledgements}

Special thanks to Mr.M.Tawfik for his technical skills for preparing histopathological slides.

\section{References}

1. Smith V, Havens R, Walsh L. Gabapentin misuse, abuse, and diversion: A systematic review. Addiction Journal. 2016; 111(7):1160-74.

2. Sendra J, Junyent T, Pellicer M. Pregabalin-induced hepatotoxicity. Annals of Pharmacotherapy Journal. 2011; 45(6):32-35. 
3. Toth C. Pregabalin: latest safety evidence and clinical implications for the management of neuropathic pain. Therapeutic advances in drug safety Journal. 2014; 5(1):38-56

4. Ruiz M, Alvarez E, Carrasco J, Olivares J, Pérez M, Rejas J. Modeling the longitudinal latent effect of pregabalin on self-reported changes in sleep disturbances in outpatients with generalized anxiety disorder managed in routine clinical practice. Drug Design, Development and Therapy Journal. 2015; 9:4329-4340.

5. Oulis $P$, Konstantakopoulos $\mathrm{G}$. Efficacy and safety of pregabalin in the treatment of alcohol and benzodiazepine dependence. Expert opinion on investigational drugs Journal. 2012;21(7):1019-1029.

6. McHugh R, Nielsen S, Weiss R. Prescription drug abuse: from epidemiology to public policy. Journal of substance abuse treatment. 2015; 48(1):1-7.

7. Schifano F, Orsolini L, Duccio G, Corkery J. Novel psychoactive substances of interest for psychiatry. World Psychiatry. 2015; 14(1):15-26.

8. Zellner N, Eyer F, Zellner T. Alarmierender Pregabalin-Missbrauch: Prävalenz im Münchener Raum, Konsummuster und Komplikationen. DMW - Deutsche Medizinische Wochenschrift. 2017;142(19):e140-e147.

9. FDA. Pregnancy and Lactation Labeling Rule Considerations for Populating Lactation Section 8.2. Retrieved on January 2020. Available at www.FDA.org.com

10. Jones AW, Mørland JG, Liu RH. Driving under the influence of psychoactive substances - A historical review. Forensic Sci Rev. 2019 Jul;31(2):103-140.

11. Olaizola I, Ellger T, Young P, Bösebeck F, Evers S, Kellinghaus C. Pregabalin-associated acute psychosis and epileptiform EEG-changes. Seizure. 2006;15(3):208-210.

12. Choi Y, Park M, Woo S, Kim U, Jung M, Kwon Y. Perverted head-shaking and positional downbeat nystagmus in pregabalin intoxication. Journal of the neurological sciences. 2014;337(1-2):243-244.

13. Fathy H, Yassa H, Almaz D, Mohamed R. Acute and Subchronic Tramadol Toxicity on Brain and Spinal Cord of Male Albino Rats. Ain Shams Journal of Forensic Medicine and Clinical Toxicology. 2013;20(1):135-145.

14. Bancrof J, Gamble M. Theory and Practice of Histological Technique, 5th edition. Edinburg, London: Churchill Livingstone; 2002, pp45-50.

15. Hahm T, Ahn H, Ryu S, Gwak M, Choi S, Kim J, et al. Combined carbamazepine and pregabalin therapy in a rat model of neuropathic pain. British Journal of Anaesthesia. 2012;109(6):968-974.

16. Lyndon A, Audrey S, Wells C, Burnell E, Ingle S, Hill R, et al. Risk to heroin users of polydrug use of pregabalin or gabapentin. Addiction. 2017;112(9):1580-1589.

17. Daly C, Griffin E, Ashcroft D, Webb R, Perry I, Arensman E. Intentional Drug Overdose Involving Pregabalin and Gabapentin: Findings from the National Self-Harm Registry Ireland, 2007-2015. Clinical Drug Investigation. 2018;38(4):373-380.

18. Lee S. Pregabalin intoxication-induced encephalopathy with triphasic waves. Epilepsy \& Behavior. 2012 Oct 1;25(2):170-3. 
19. Anand P, Kaplan P. Triphasic Waves and Encephalopathy in the Setting of Pregabalin Toxicity. Journal of Clinical Neurophysiology. 2018;35(6):515-7.

20. Parekh M, Dash G, Ahamed I. Pregabalin Toxicity Manifesting as Reversible Encephalopathy with Continuous Triphasic Waves in Electroencephalogram. Clinical Neuropharmacology. 2017;40(5):226228.

21. Salih A, Al-mahdawi F, Al-salihi A. Teratological effect of pregabalin drug on the prenatal development of the cerebellum in the albino rats. International Journal of Recent Sci. 2014; 5:13811385.

22. Magar M, Ebada M, Al-Gizawy M. Study of the Effect of Prenatal Administration of Pregabalin on Cerebellar Cortex of Albino Rat's Offspring and the Possible Protective Role of Folic Acid. Al-Azhar International Medical Journal, 2020; 1(2): 133-139. doi: 10.21608/aimj.2020.29636.1220.

23. Badawy GM, Atallah MN, Sakr SA. Effect of gabapentin on fetal rat brain and its amelioration by ginger. Heliyon. 2019 Sep 4;5(9): e02387.

24. Hoxha E, Balbo I, Miniaci M, Tempia F. Purkinje Cell Signaling Deficits in Animal Models of Ataxia. Frontiers in Synaptic Neuroscience. 2018; 10:6.

25. Yoo L, Matalon D, Hoffman R, Goldfarb D. Treatment of Pregabalin Toxicity by Hemodialysis in a Patient with Kidney Failure. American Journal of Kidney Diseases. 2009; 54(6):1127-1130.

26. Choi Y, Park M, Woo S, Kim U, Jung M, Kwon Y. Perverted head-shaking and positional downbeat nystagmus in pregabalin intoxication. Journal of the neurological sciences. 2014;337(1-2):243-244.

27. Slocum G, Schult R, Gorodetsky R, Wiegand T, Kamali M, Acquisto N. Pregabalin and paradoxical reaction of seizures in a large overdose. Toxicology Communications. 2018;2(1):19-20.

28. Arroyo S, Anhut H, Kugler A, Lee C, Knapp L, Garofalo E, et al. Pregabalin add-on treatment: a randomized, double-blind, placebo-controlled, dose-response study in adults with partial seizures. Epilepsia. 2004;45(1):20-27.

29. Venkataraman P, Selvakumar K, Krishnamoorthy G, Muthusami S, Rameshkumar R, Prakash S. Effect of melatonin on PCB (Aroclor 1254) induced neuronal damage and changes in $\mathrm{Cu} / \mathrm{Zn}$ superoxide dismutase and glutathione peroxidase-4 mRNA expression in cerebral cortex, cerebellum and hippocampus of adult rats. Neuroscience Research. 2010;66(2):189-197.

30. Hoxha E, Balbo I, Miniaci M, Tempia F. Purkinje Cell Signaling Deficits in Animal Models of Ataxia. Frontiers in Synaptic Neuroscience. 2018; 10:6.

31. Jeong S, Kim Y, Lee J, Jo H, Lee A, Kim J. Transient Positive Horizontal Head Impulse Test in Pregabalin Intoxication. Journal of epilepsy research. 2015;5(2):101-103.

32. Patel R, Dickenson A. Mechanisms of the gabapentinoids and a $2 \delta-1$ calcium channel subunit in neuropathic pain. Pharmacology research \& perspectives. 2016;4(2): e00205.

\section{Figures}




\section{Figure 1}
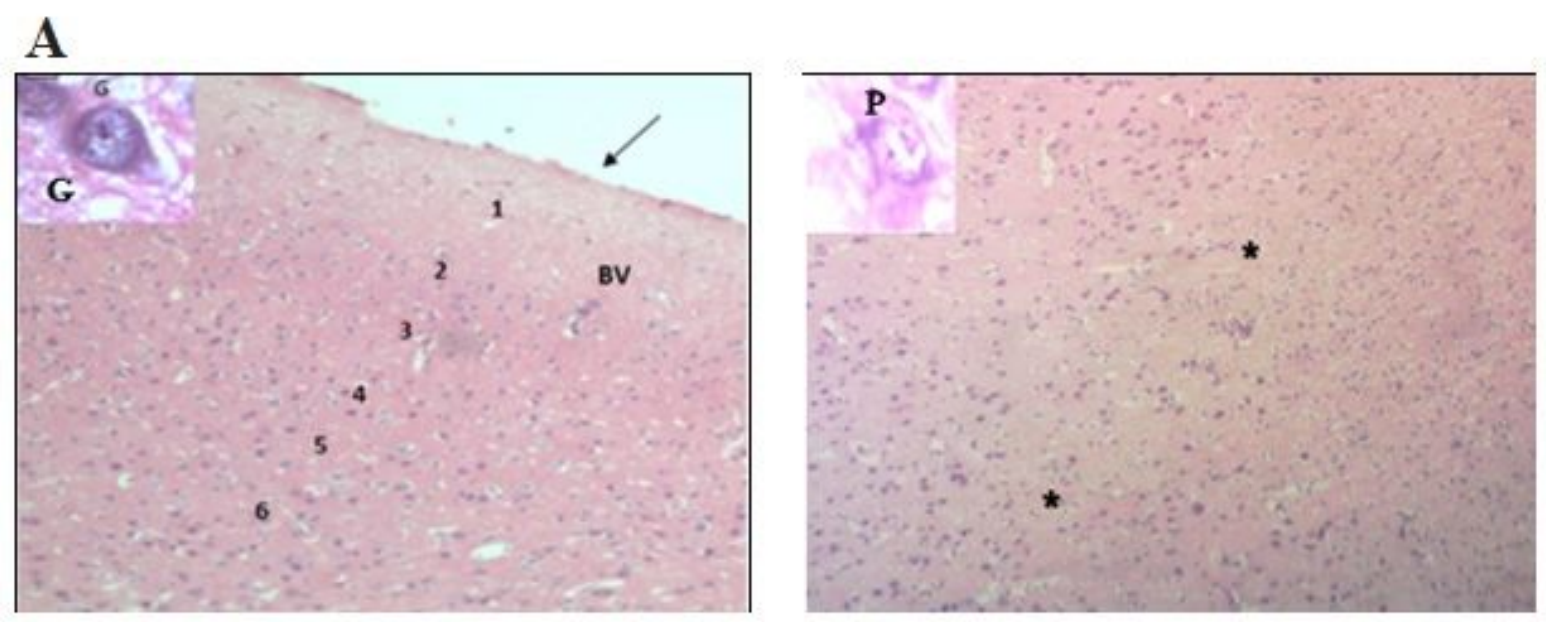

\section{B}
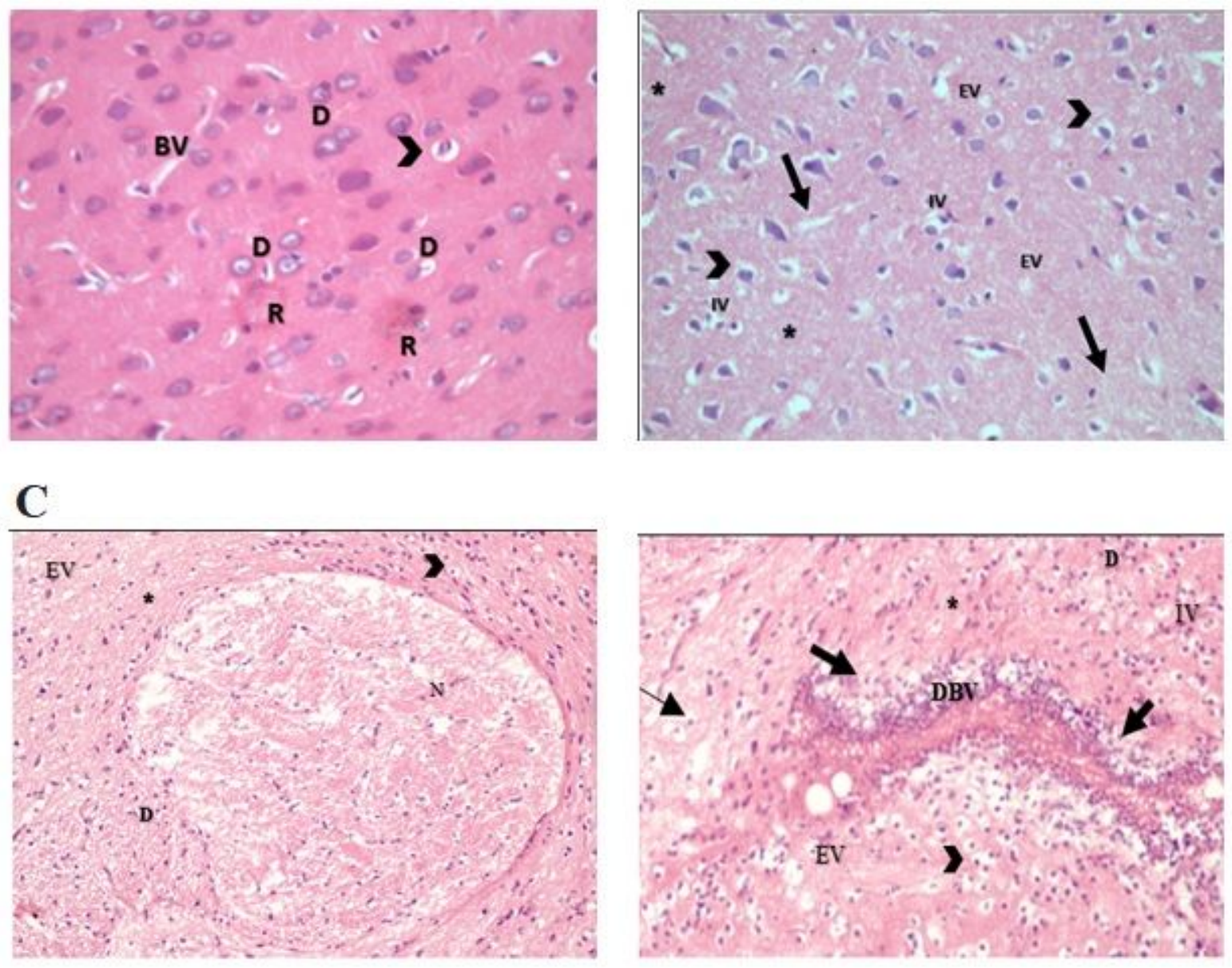

\section{Figure 1}

Representative figures heamtoxylin and eosin stained sections of cerebral cortex in control, acute and chronic toxicity groups. (Left sided figure; 20x \& right sided figure; 40x) A; Control group Section of control rat cerebral cortex showing normal pia matter (black arrow), grey matter layers; molecular layer (1), outer granular layer (2), outer pyramidal layer (3), inner granular layer (4), inner pyramidal layer(5) and the plemorphic layer (6), homogenous neuropil (black star *) and blood vessels (BV). Inset showing 
pyramidal cells $(P)$ and granular cells $(G), 100 x$. B; Acute toxicity group Photomicrographs of sections from the cerebral cortex of adult albino rats with acutely intoxicated with pregabalin LD50 (II) for 24 hours, showing astrocytes with hypercellularity and irregular distribution, degenerated neurons (D), homogenous neuropil with slight vacuolation and pericellular halos (arrowheads). In addition, there are intracellular vacuoles (IV), extracellular vacules (EV), intersitial edema (thick black arrow) and dystrophic red neurons (R). C; Chronic toxicity group Photomicrographs of sections from the cerebral cortex of adult albino rats with chronic intoxication with pregabalin LD50 (II) for twelve weeks, showing degenerated neurons (D), homogenous neuropil with vacuolation (*), intracellular vacuoles (IV), extracellular vacuoles $(E V)$, interstitial edema and inflammatory infiltrate (Thin black Arrow), pericellular halos (Arrowhead), necrosis $(\mathrm{N})$ and dilated blood vessels (DBV). 


\section{Figure 2}
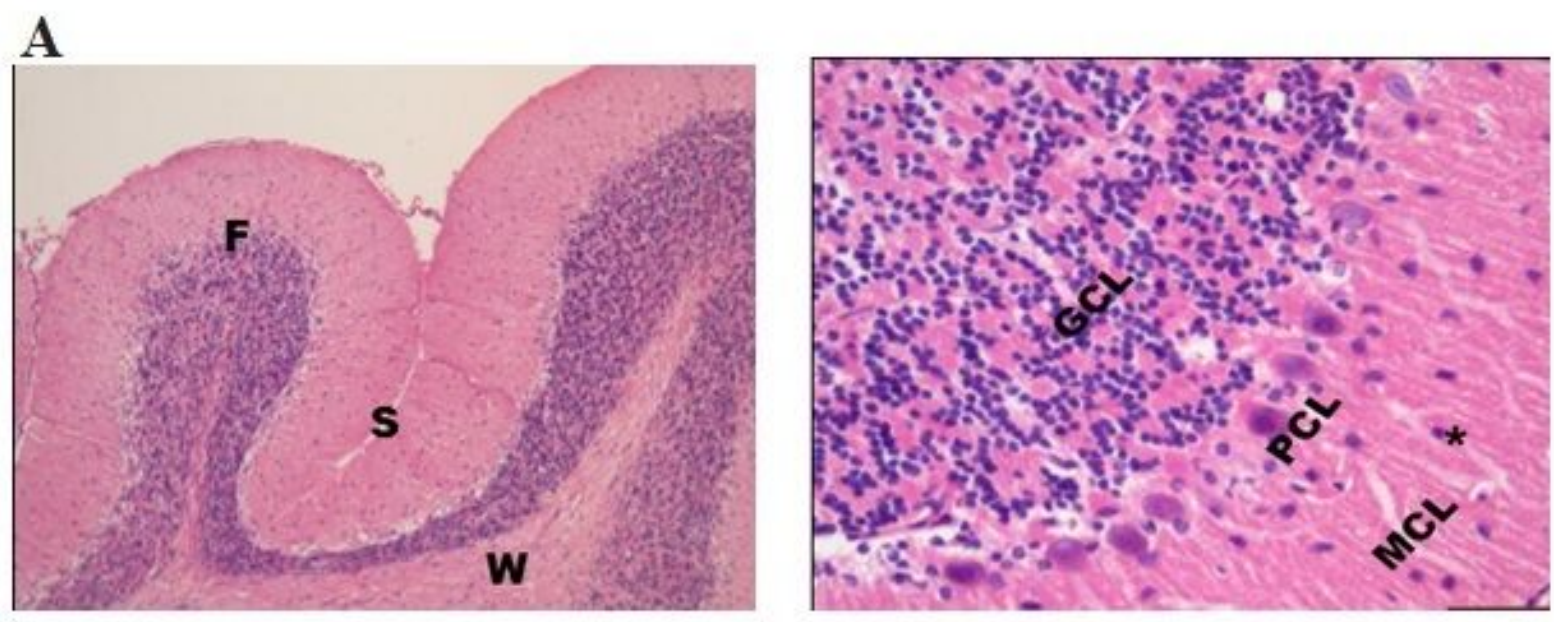

\section{B}
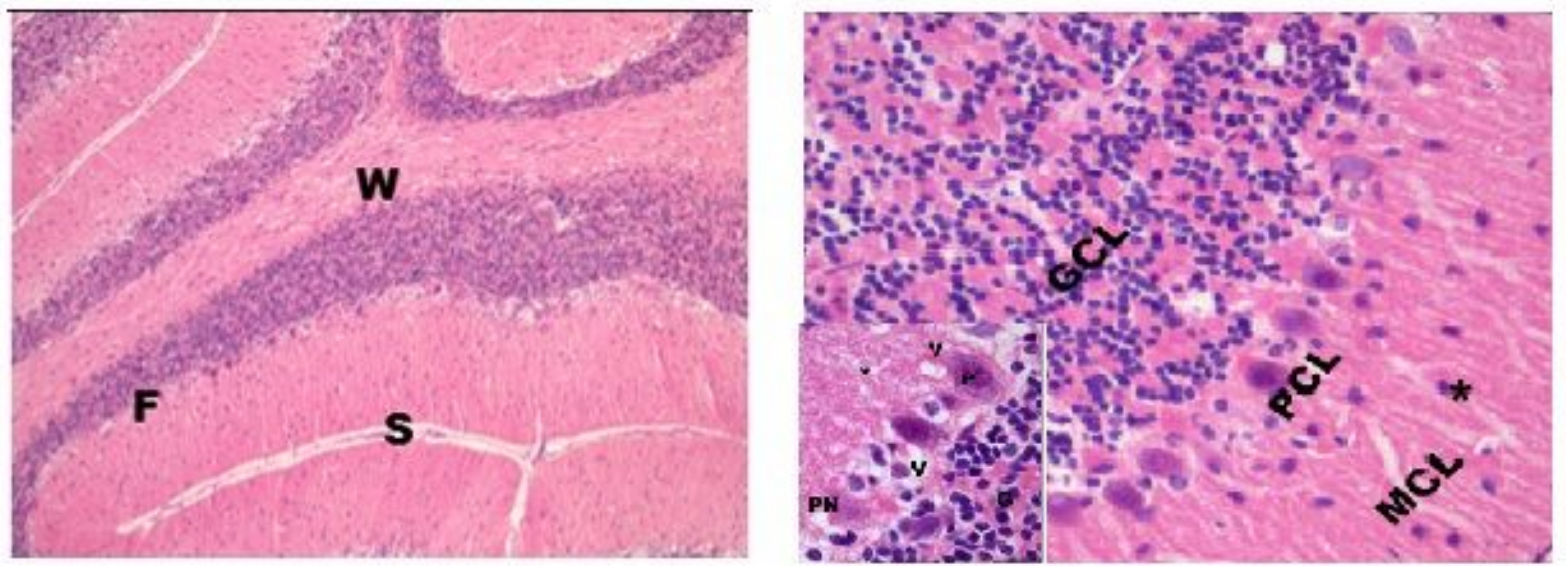

\section{C}
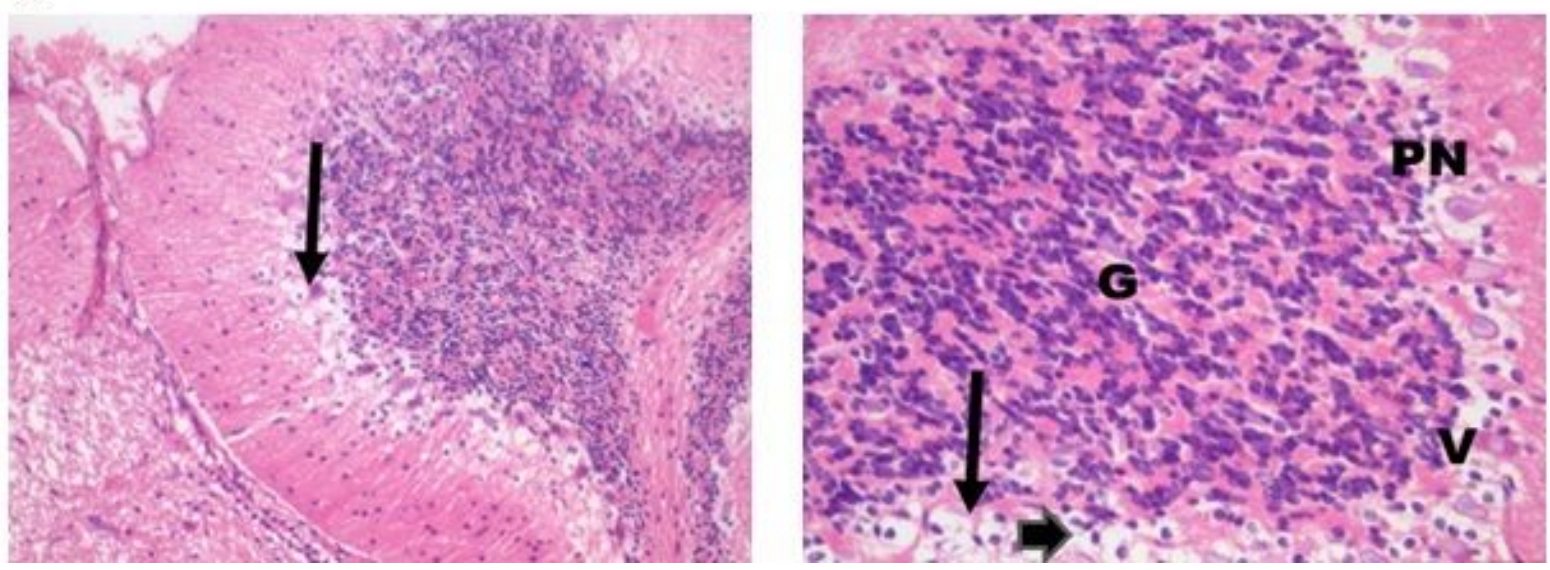

Figure 2

Representative figures heamtoxylin and eosin stained sections of cerebellum in control, acute and chronic toxicity groups. (Left sided figure; 20x \& right sided figure; 40x) A; Control group Section of control rat cerebellum showing normal folia (F) separated by narrow sulci (S), uniform white matter (W), wellorganized three layers of cerebellar cortex; the molecular layer (MCL), the Purkinje cell layer (PCL) and the granular layer (GCL). The cerebellar cortex showing stellate (Sc), basket cells (B), large pyriform Purkinje 
cells $(P)$, granular cells $(G)$ and surrounding neuropil $\left(^{*}\right)$. B; Acute toxicity group Photomicrographs of sections from the cerebellum of adult albino rats with acutely intoxicated with pregabalin LD50 (II) for 24 hours, showing preserved architecture of cerebellar cortex layers; the molecular layer (MCL), the Purkinje cell layer $(\mathrm{PCL})$ and the granular layer $(\mathrm{GCL})$ with surrounding neuropil $\left({ }^{*}\right)$. Some Purkinje cells $(\mathrm{PN})$ are distorted and shrunken with vacuoles (V). (Incet, 100x) C; Chronic toxicity group Photomicrographs of sections from the cerebellum of adult albino rats with chronic intoxication with pregabalin LD50 (II) for twelve weeks, showing degenerated Purkinje cells (PN), vacuoles $(\mathrm{V})$ and pericellular halos (thick black arrows), with interstitial edema (thin black arrows).

\section{Supplementary Files}

This is a list of supplementary files associated with this preprint. Click to download.

- Supplemebtaryinformation.docx 